\title{
Quantifying The Impact of Inhalational Burns: A Prospective Study
}

\section{Si Jack CHONG, Yee Onn KOK, Rosanna TAY, Kok Chai TAN Department of Plastic, Reconstructive and Aesthetic Surgery, Singapore General Hospital}

\section{Background}

Inhalational injury is a major cause of morbidity and mortality in burns patients.

\section{Methods}

A prospective study was done on consecutive admissions to a major burns centre over 15 months from January 2015 - March 2016.

Diagnosis of inhalational injury

\begin{tabular}{l|l}
$\begin{array}{l}\text { Symptoms and signs of } \\
\text { inhalational iniury }\end{array}$ & Nasoendoscopy \\
$\begin{array}{l}\text { - Hoarseness of voice } \\
\text { - Sore throat }\end{array}$ & - Airway erythema/edema \\
- Dyspnea & - Soot in airways \\
- Painful respirations & appearance of vocal cords \\
- Carbonaceous sputum & \\
- Tachypnea & \\
- Stridor & \\
- Facial burns/ mucosal burns of & \\
- lips and mouth & \\
- Singed facial hair/ nasal hair & \\
\end{tabular}

\section{Results}

\begin{tabular}{|l|c|c|c|}
\hline & $\begin{array}{c}\text { Cutaneous } \\
\text { burns only }\end{array}$ & $\begin{array}{c}\text { Inhalational } \\
\text { burns }\end{array}$ & P value, U \\
\hline $\begin{array}{l}\text { Number of } \\
\text { patients }\end{array}$ & 167 & 35 & - \\
\hline $\begin{array}{l}\text { TBSA } \\
\text { (median) }\end{array}$ & 5 & 9 & $0.036, \mathrm{U}=3582$ \\
\hline Age(mean) & 38.8 & 44.1 & $0.176, \mathrm{U}=2451$ \\
\hline $\begin{array}{l}\text { Surgeries } \\
\text { (median) }\end{array}$ & 1.000 & 3.000 & $0.003 . \mathrm{U}=3552$ \\
\hline $\begin{array}{l}\text { Length of } \\
\text { stay } \\
\text { (median) }\end{array}$ & 8 & 21 & $0.004, \mathrm{U}=3582$ \\
\hline $\begin{array}{l}\text { Length of } \\
\text { ICU } \\
\text { stay(median) }\end{array}$ & 0 & 3 & $<0.001, \mathrm{U}=4785$ \\
\hline $\begin{array}{l}\text { Days of IV } \\
\text { antibiotics } \\
\text { (median) }\end{array}$ & 3 & 9.5 & $0.014, \mathrm{U}=3552$ \\
\hline
\end{tabular}

In-hospital mortality Burn wound infection Pneumonia $\mathrm{p}<0.001 \quad \mathrm{p}=0.004 \quad \mathrm{p}<0.001$

$51.4 \%$

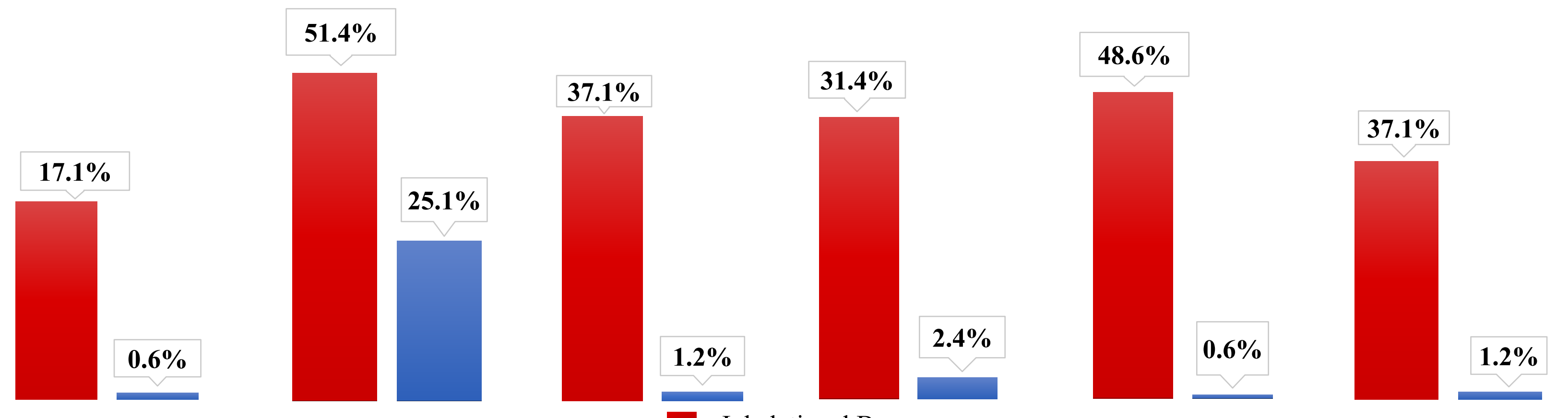

Inhalational injury predicted AKI with an adjusted odds ratio (OR) of 17.43 (95\% CI 3.07-98.87, $\mathrm{p}<0.001)$, ARDS, OR $106.71(12.73-894.53, \mathrm{p}<0.001)$ and Pneumonia, OR $13.87(2.32-82.94, \mathrm{p}=0.004)$.

\begin{tabular}{|c|c|c|c|c|c|c|}
\hline & \multicolumn{3}{|c|}{ Inhalational injury } & \multicolumn{3}{|c|}{$\begin{array}{c}\text { Inhalational injury, adjusted } \\
\text { for TBSA }\end{array}$} \\
\hline & OR & $95 \% \mathrm{CI}$ & $\mathrm{p}$ value & $\begin{array}{c}\text { Adj. } \\
\text { OR }\end{array}$ & $95 \% \mathrm{CI}$ & $\mathrm{p}$-value \\
\hline $\begin{array}{l}\text { All } \\
\text { complications }\end{array}$ & 8.33 & $\begin{array}{l}3.62- \\
19.17\end{array}$ & $<0.001$ & 5.31 & $\begin{array}{l}2.17- \\
12.98\end{array}$ & $<0.001$ \\
\hline Pneumonia $^{1}$ & 48.75 & $\begin{array}{l}10.30- \\
230.55\end{array}$ & $<0.001$ & 13.87 & $\begin{array}{l}2.32- \\
82.94\end{array}$ & 0.004 \\
\hline ARD & $\begin{array}{c}156.7 \\
8\end{array}$ & $\begin{array}{c}19.69- \\
1248.17\end{array}$ & $<0.001$ & 106.71 & $\begin{array}{l}12.73- \\
894.53\end{array}$ & $<0.001$ \\
\hline $\mathbf{A K I}^{3}$ & 48.75 & $\begin{array}{l}10.31- \\
230.55\end{array}$ & $<0.001$ & 17.43 & $\begin{array}{l}3.07- \\
98.87\end{array}$ & $<0.001$ \\
\hline Bacteremia $^{\wedge}$ & 18.68 & $\begin{array}{l}5.50- \\
63.39\end{array}$ & $<0.001$ & 2.39 & $\begin{array}{l}0.38- \\
15.04\end{array}$ & $\mathrm{p}>0.05$ \\
\hline $\begin{array}{l}\text { Burn wound } \\
\text { infection } \wedge\end{array}$ & 3.15 & $\begin{array}{l}1.49- \\
6.67\end{array}$ & 0.003 & 1.28 & $\begin{array}{l}0.49- \\
3.35\end{array}$ & NS \\
\hline
\end{tabular}

${ }^{1} \mathrm{ABA}$ (American Burns Association) guidelines. $\quad{ }^{2}$ Berlin criteria

${ }^{3}$ AKIN (Acute Kidney Injury Network) classification stage 2 and above

OR: Odds ratio. CI Confidence interval. NS Non-significant

\section{Bacteriology}

Acinetobacter baumannii was the most frequently cultured bacteria in sputum, blood and tissue cultures with inhalational injury. Gram-negative bacteria were predominantly cultured from tissue in patients with inhalational injury, whereas gram-positive bacteria were predominantly cultured from tissue in patients without inhalational injury.

Pneumonia Inhalational injury $\mathrm{n}=13 \quad$ Non inhalational injury $\mathrm{n}=2$

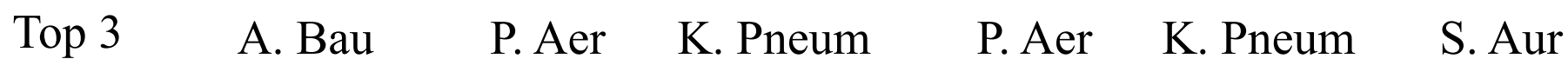
$\begin{array}{llllll}\text { (positive } \quad 53.8 \% & 38.5 \% & 23.1 \% & 50.0 \% & 50.0 \% & 50.0 \%\end{array}$ cultures/

total

cultures)
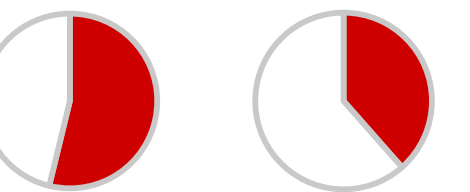

Wound Infection Inhalational injury $\mathrm{n}=18$

\section{Top 3 A. Bau P. Aer S. Aur}
cultures $22.2 \%$
$22.2 \%$
$16.7 \%$
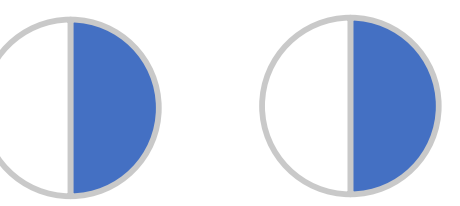

Non inhalational injury $\mathrm{n}=42$
S. Aur P. Aer
A. Bau $35.7 \% \quad 28.6 \%$

$21.4 \%$

\section{Conclusion}

Inhalational injury accompanying burns significantly increases the length of stay, mortality and complications (AKI, ARDS, infection and sepsis).
Bacteraemia
$\mathrm{p}<0.001$
ARDS
$\mathrm{p}<0.001$
AKI
$\mathrm{p}<0.001$

1 ARDS Definition Task Force, Ranieri VM, Rubenfeld GD, Thompson BT, Ferguson ND, Caldwell E, Fan E, Camporota L, Slutsky AS. Acute respiratory distress syndrome: the Berlin Definition. JAMA. 2012 Jun 20;307(23):2526-33. doi: 10.1001/jama.2012.5669.

2 Mehta RL, Kellum JA, Shah SV, Molitoris BA, Ronco C, Warnock DG, Levin A, Acute Kidney Injury Network Acute Kidney Injury Network: report of an initiative to improve outcomes in acute kidney injury. Crit Care. 2007;11(2):R31. 